NBER WORKING PAPER SERIES

\title{
EVIDENCE ABOUT THE POTENTIAL ROLE FOR AFFIRMATIVE ACTION IN HIGHER EDUCATION
}

\author{
Braz Camargo \\ Todd Stinebrickner \\ Ralph Stinebrickner \\ Working Paper 13342 \\ http://www.nber.org/papers/w13342
}

\author{
NATIONAL BUREAU OF ECONOMIC RESEARCH \\ 1050 Massachusetts Avenue \\ Cambridge, MA 02138 \\ August 2007
}

We would like to thank John Bound, Kerwin Charles, Stacy Dickert-Conlin, Lance Lochner and numerous seminar participants for very useful comments and suggestions. We are grateful for support from The Mellon Foundation, The University of Kentucky Center for Poverty Research, The Spencer Foundation, The National Science Foundation, The Social Sciences and Humanities Research Council, and Berea College. The views expressed herein are those of the author(s) and do not necessarily reflect the views of the National Bureau of Economic Research.

(C) 2007 by Braz Camargo, Todd Stinebrickner, and Ralph Stinebrickner. All rights reserved. Short sections of text, not to exceed two paragraphs, may be quoted without explicit permission provided that full credit, including $(\mathcal{O}$ notice, is given to the source. 
Evidence about the Potential Role for Affirmative Action in Higher Education

Braz Camargo, Todd Stinebrickner, and Ralph Stinebrickner

NBER Working Paper No. 13342

August 2007

JEL No. I2,J0,J15,K0

\begin{abstract}
$\underline{\text { ABSTRACT }}$
In two recent cases involving the University of Michigan (Gratz v. Bollinger and Gruttinger v. Bollinger), the Supreme Court examined whether race should be allowed to play an explicit role in the admission decisions of schools. The arguments made in support of affirmative action admission policies in these cases and others raise two fundamental questions. First, do students actually have incorrect beliefs about individuals from different races at the time of college entrance? Second, if students do have incorrect beliefs at the time of college entrance, can diversity on a college campus change these beliefs? While a small literature has recently shed some light on the second question, no previous work has been able to provide direct evidence about the first one. In this paper we examine the first question by taking advantage of unique data collected specifically for this purpose.

Braz Camargo

Department of Economics

The University of Western Ontario

London, Ontario Canada N6A 5C2

bcamargo@uwo.ca

Todd Stinebrickner

Department of Economics

University of Western Ontario

London, Ontario, N6A 5C2

CANADA

and NBER

trstineb@uwo.ca

Ralph Stinebrickner

Dept. of Mathematics

Berea College

Berea, KY 40404

ralph_stinebrickner@berea.edu
\end{abstract}




\section{Introduction}

In two recent cases involving the University of Michigan (Gratz v. Bollinger and Gruttinger v. Bollinger), the Supreme Court examined whether race should be allowed to play an explicit role in the admission decisions of schools. In these court cases and others, the prominent argument in support of affirmative action admission policies has been that racial diversity strengthens the quality of education offered to all students. Underlying this argument is the notion that universities educate students in a broad sense. Educational benefits arise if interactions between students of different races improve preparation for life after college by, among other things, fostering mutual understanding and correcting misperceptions.

A small literature has recently shed some light on one question of direct relevance to this argument - is diversity on a college campus effective in changing students' beliefs about individuals from different races? For example, related to the notion that interactions between individuals of different races are a necessary (but perhaps not sufficient) condition for changing beliefs, Marmaros and Sacerdote (2006) examine whether the quantity of email that a person exchanges with a student of a different race is influenced by whether the two students are assigned to the same freshman dorm. Likewise, Arcidiacono et. al (2006) find that white students are more likely to "know two or more blacks well" if they attend schools that admit a higher percentage of black students. Boisjoly et. al (forthcoming) measure post-college attitudes directly and find that being assigned a black roommate causes a white student to become more empathetic towards minorities.

However, to the best of our knowledge, no previous work has been able to provide direct evidence about a second question that is perhaps of even more fundamental relevance to the argument in the first paragraph - do the types of individuals who choose to enter college 
actually have incorrect beliefs about individuals from different races at the time of college entrance ${ }^{1}$ While it seems at least possible that incorrect beliefs exist, the reality is that we simply do not know whether this is the case or not. For example, for reasons that will be discussed throughout this paper, it does not seem prudent to assume that either formal or informal evidence of substantial racial segregation on college campuses should be viewed as Prima Facie evidence of incorrect beliefs. Further, one can think of factors that may tend to mitigate the extent to which incorrect beliefs are prevalent. Among these, it seems probable that the students who choose to enter college will typically have had a relatively wide range of experiences by the time of matriculation and will tend to be the most open-minded and informed of their age group.

This paper is able to provide evidence about this second question by taking advantage of unique longitudinal survey and administrative data that we have collected at Berea College where the roommate assignment process generates a useful source of exogenous variation in interracial interactions. Located in Central Kentucky, Berea College was founded in 1855 as the first interracial and co-educational college in the South and operates under a mission of "promoting understanding and kinship among all people." As some evidence of Berea's strong reputation for promoting understanding and harmony between individuals from different races, the daughter of South African Archbishop Desmond Tutu is a graduate of Berea and he served as Berea's 2005 graduation speaker. In addition, Berea College was recently named the 13 th best college for African-American students in a DayStar ranking published in Black Enterprise magazine, with about half of the schools ranked above it

\footnotetext{
${ }^{1}$ Although not the focus of their paper, the finding by Boisjoly et. al (forthcoming) that interactions with black roommates influence attitudes of white students towards minorities has some indirect bearing on this question.
} 
being historically black colleges. ${ }^{2}$ Given this history and reputation, it seems likely that individuals who select Berea would be relatively open to relationships with individuals from different races. Thus, if information problems exist between different races at Berea at the time of college entrance, it seems reasonable to believe that such problems probably also exist elsewhere at the time of college entrance.

We consider a particular belief - whether a student perceives that, on average, his friendship compatibility is higher with students of his race than it is with students of other races that likely incorporates a variety of general views about individuals of other races. We begin by taking an "actions speak larger than words" approach of trying to infer beliefs about interracial friendship compatibility from observed friendship choices, an approach that is possible because our data are unique among higher education sources in that they allow us to directly identify each person's friends. ${ }^{3}$ The fundamental identification difficulty in this exercise is that friendship choices are influenced not only by beliefs about interracial friendship compatibility, but also by the process which governs how students meet potential friends. For example, a student who believes that, on average, he is equally compatible with students of his race and other races would still have a disproportionate number of friends

\footnotetext{
${ }^{2}$ The criteria used to rank a school includes the academic and social environment for African-American students at the school. The Berea reputation as a good environment for black students is quite pervasive in the college choice literature. As another example, the Students' Guide to Colleges, which bases its rankings on the opinions of students, highlights the following quote from a student at Berea, "One thing that Berea does do extremely well is welcome in black students.... Black students really couldn't find a more open and accepting college than Berea with the exception of a historically black college like Morehouse or Howard."

${ }^{3}$ There is a literature in higher education whose primary goal is to to document the amount of interracial sorting using indirect approaches. Mayer and Puller (2006) use information obtained from Facebook.com. Marmaros and Sacerdote (2006) measure the quantity of email that is exchanged between pairs of students. These papers cannot provide any information about whether observed sorting is due to correct or incorrect perceptions. Most similar to the data used in this paper are the Addhealth data that identifies the friends of high school students (Fryer and Torelli (2006)).
} 
of his race if he is involved in clubs, activities, social circles, or classes in which he meets a disproportionate number of students of his race. We are able to deal with this difficulty by taking advantage of the flexibility of our data collection efforts which allowed us to observe our first friendship choices at a time - immediately before classes began in the students' freshman year - when institutional details related to the orientation program and housing assignment process suggest that the process by which a person meets potential friends will, to a close approximation, be unconditionally random. ${ }^{4}$

Our friendship data indicates that very substantial racial segregation exists in friendships at the start of classes. As discussed in Section 3, although $15.8 \%$ of students at Berea are black, $69.6 \%$ of the best friends of black students and $66.8 \%$ of "all" friends of black students are black at the start of classes, while only $5.7 \%$ of the best friends of white students and $9.8 \%$ of "all" friends of white students are black at the start of classes. In order to provide guidance for thinking about the possible underlying reasons for this finding, in the remainder of Section 3 we appeal to a simple but flexible model of friendship-making under uncertainty. Under seemingly reasonable specifications, the model suggests that racial sorting occurs because some students believe they are, on average, more compatible with students of their own race than with students of different races.

In order to determine whether such a perception is incorrect, it is necessary to characterize the truth about interracial friendship compatibility. To do this, in Section 4 we take advantage of a unique experiment that arises because students at Berea are randomly (and unconditionally) assigned roommates in their freshman year. In essence, this experiment

\footnotetext{
${ }^{4}$ Being able to observe friendship information at pre-chosen times for groups of particular interest is an important advantage of our survey collection efforts. For example, Marmaros and Sacerdote (2006) use a measure of social (email) interaction which is constructed by aggregating over a fourteen month period. Further, they observe this email measure for only $11 \%$ of Dartmouth's freshman class.
} 
forces some students to learn about their friendship compatibility with an individual of a different race. We find that, in reality, white students and black students are very compatible as friends with white students being as likely to eventually become close friends with randomly assigned black roommates as they are to eventually become close friends with randomly assigned white roommates. Thus, if the racial sorting at the start of classes is indeed generated by beliefs that average friendship compatibility varies with the race of one's friends, then incorrect information exists and there is a potentially important role for policy.

In an effort to be cautious, in Section 5 we explore some alternatives to the explanation that the observed sorting arises because some students enter college with a belief that they are, on average, more compatible with students of the same race than students of other races. Given that from friendship outcomes alone it would never be possible to rule out with certainty all conceivable alternative explanations for the observed sorting, it is desirable to provide direct evidence that complements our "actions speak louder than words" approach. To do this, in Section 6 we develop a unique survey approach which addresses the concern that systematic response errors would likely be prevalent if students were asked directly about their beliefs about interracial friendship compatibility. Consistent with our earlier conclusions, we find evidence of the type of misperception that could motivate policy action. However, inconsistent with some policy discussions that emphasize the virtues of alleviating misperceptions of the majority group, we find evidence that, in this case, black students have incorrect perceptions about their compatibility with white students.

While our paper suggests a potentially important role for policy, a separate, difficult question, is whether a policy of combining students of different races within a particular institution will lead to changes in perceptions. In our conclusion, Section 7, we examine what our data, which provide friendship observations over the entire period that a student 
remains in school, allow us to say about this issue. We also discuss how the conclusions of this work should be shaped by the reality that we are studying one particular school.

\section{The Berea Panel Study}

The data come from the Berea Panel Study (BPS) which, as described in detail in Stinebrickner and Stinebrickner (2004, 2006a, 2006b), was initiated by Todd Stinebrickner and Ralph Stinebrickner with the goal of understanding a variety of decisions that students from low income families make after entering college. The BPS consists of two cohorts that entered Berea College in the fall of 2000 and 2001, respectively, and were surveyed between ten and twelve times each year while in school. Unique identifiers allow the survey data to be matched with student information from the school's administrative database.

Of particular importance for this paper, the BPS collected substantial information about friends and roommates four times each year while students were in school. In this paper, we utilize data from both cohorts in a couple of specific situations where it is particularly advantageous to do so for reasons related to sample size. However, for reasons discussed in the Introduction, we focus primarily on the second (2001) cohort because it was asked to provide friendship information on the baseline BPS survey which took place immediately before classes began in the freshman year. The participation rate for the baseline survey was approximately .90 for the 2001 cohort and Table 1 shows descriptive statistics for our sample of 375 students from this cohort. Approximately $43 \%$ of students at Berea are male and $15.8 \%$ of students are black. We note that, because the very large majority of non-black students are Caucasian, we combine all non-black students into a group that we refer to as "white" in the remainder of the paper. Consistent with the mission of the school to provide 
an education to students of "great promise but limited economic resources," students at Berea are all relatively poor with an average family income of only approximately $\$ 25,000$. The reality that students are quite homogenous in this respect is noteworthy for reasons discussed later.

\section{Inferring Beliefs at the Time of Entrance}

In this section we examine what observed friendship choices at the start of classes imply about beliefs about average interracial friendship compatibility at the time of college entrance. We first document the amount of racial sorting at the start of classes. We then view the sorting that is observed through the lens of a simple, but flexible, model of friendship-making under uncertainty and use this model to make inference about beliefs.

\subsection{Descriptive Evidence About Sorting at the Time of Entrance}

At the time that classes begin in the freshman year, we elicited friendship information for students in the 2001 cohort by using the following question on our baseline BPS survey:

Question A. Please list the names of the four people you currently consider your best friends at Berea College and provide information about where you met each of them. Please list in order with the person you would consider your best friend first.

First Name Last Name Where I met this person Circle ONE
1. $\_-$Hometown At Berea College Other (specify)
2. $\longleftarrow$ Hometown At Berea College Other (specify)
3.


The number of observations for which friendship information is observed (354) is slightly smaller than the total sample size (375) because two students indicated that they had no friends and nineteen students listed no friends that could be matched with individuals in our student data base. The latter arises primarily because, at of the time of our baseline survey, students had been at Berea for a short time and some individuals did not know both the first and last names of some of their friends. Nonetheless, students were reasonably knowledgeable about the names of their friends even at this early point in their college careers; we were able to find approximately $75 \%$ of the listed friends in our official database. Not surprisingly, the proportion of friends we were able to match increased dramatically (to approximately 95\%) in surveys subsequent to the the baseline survey.

Table 2 shows that a very significant amount of sorting by race is present at the start of classes when we characterize sorting using the person that is listed as the best friend in Question A. Pooling males and females and computing sample proportions, the first column shows that $69.6 \%$ of black students in our sample have best friends who are black while only $5.7 \%$ of white students in our sample have best friends who are black. If sorting were purely random, then, in large samples, the proportion of black students who have black best friends would be $15.8 \%$, which is also what the proportion of white students with black best friends would be. Statistical tests overwhelmingly reject the hypothesis that the first condition is true, the hypothesis that the second condition is true, and the hypothesis that the two conditions are jointly true. ${ }^{5,6}$ The first column of Table 3 shows similar results at the

\footnotetext{
${ }^{5}$ The test of the null hypothesis that the proportion of black students who have black best friends is $15.8 \%$ has a standard normal test statistic of 11.334. The test of the null hypothesis that the proportion of white students who have black best friends is $15.8 \%$ has a standard normal test statistic of 4.778 . A test that the proportion of black students who have black best friends is the same as the proportion of white students who have black best friends has a standard normal test statistic of 12.030.

${ }^{6}$ Sixty percent of male black students in the sample have black best friends while $77 \%$ of female black
} 
start of classes when we characterize sorting using information about all individuals that are listed as friends in Question A. Pooling males and females we find that, on average, 66.8\% of the friends listed by a black student are black while only $9.8 \%$ of the friends listed by a white student are black.

As will become clear at the end of this section, it is of interest to know whether there exists evidence that a substantial amount of the sorting in the first columns of Table 2 and Table 3 arises because individuals make friendship decisions on the basis of other variables that are strongly correlated with race. The second column of Table 2 again examines the proportion of students who have a black best friend, but uses a linear probability model, with whether a person's best friend is black as the dependent variable, to control for a variety of other characteristics that we are able to observe and could be correlated with race. The second column of Table 3 again examines the proportion of a student's friends who are black, but uses a regression model, with the proportion of a student's friends that are black as the dependent variable, to control for the same set of characteristics. In both Table 2 and Table 3, the entries related to the WHITE and BLACK variables remain virtually unchanged when the additional characteristics are added.

\subsection{Explaining Sorting}

We now propose a model of friendship-making under uncertainty with the goal of inferring beliefs about interracial friendship compatibility at the time of college entrance from the sorting observed in Section 3.1. Given that the ultimate goal is to compare these beliefs to students in the sample have black best friends. Given that this difference is not statistically significant at traditional levels, we do not pay specific attention to differences by sex in the remainder of the paper, although we do find statistically different sorting patterns by sex at some points after the first year. 
what we discover about actual interracial friendship compatibility from the natural experiment in Section 4, we find it natural to phrase the question of interest in this subsection as follows: "for what values of actual interracial friendship compatibility would the model predict that racial sorting would only be possible if some students are incorrectly pessimistic about interracial friendship compatibility?"

Payoffs Students in college receive utility from friendships. At any point in time, a student can have at most one (best) friend. The flow utility that student $i$ receives from a friendship with student $j$ is a function of the quality $\theta_{i, j}$ of the match between $i$ and $j$. This quality depends on a variety of characteristics of $j$. Characteristics of relevance may include, for instance, $j$ 's sense of humor and other personality traits, religious and political views, hobbies, interests, and past experiences. The key point is that many of these friendship-relevant characteristics are not easily observable at the time two people initially meet so that $i$ does not know the value of $\theta_{i, j}$ when she first meets $j$. In order to simplify the exposition, we take this point to an extreme by assuming that the only characteristic that can be initially observed is a person's race (black or white). We discuss later why our conclusions are not sensitive to this assumption. The quality of the match between $i$ and $j$ also depends on $i$ 's own characteristics but, for ease of exposition, from now on, with the exception of the next section, we make this implicit in our notation and index match quality and other relevant variables by $j$ only.

We assume that students do not care about race per se, but may be more likely to find the characteristics that they care about among students of a particular race. More specifically, we posit that $\theta_{j}=v_{j}$ when $j$ is of the same race as $i$ and $\theta_{j}=\mu+v_{j}$ when $j$ is of the opposite race as $i$, where $\mu$ is a fixed term that can depend only on $i$ 's race and 
the $v_{j}$ are i.i.d. normal with mean zero and variance $\sigma_{v}^{2}$ that is the same for all students in college. ${ }^{7}$ Hence, for each race the average within-race match quality is higher than the average interracial match quality when $\mu<0$ and lower when $\mu>0$. Students don't know $\mu$ and start college with a prior belief about $\mu$ that is normally distributed with mean $m_{\mu}$ and variance $\sigma_{\mu}^{2}$, where these quantities need not be the same for all students. Then, the objective in what follows is to compare beliefs, $m_{\mu}$, with the truth, $\mu$.

Choosing Friends Students arrive at college for an orientation program before classes begin in their freshman year, at the end of which they complete the baseline BPS survey. We assume that each student is assigned to an orientation group with $N>1$ other students and spends orientation with this group. We note that this orientation group is a somewhat artificial construct meant to represent the group of people that would be encountered regularly during the orientation period. As such, it would include, for example, not only students assigned to one's official orientation group, but also students that have been assigned to the same dorm floor and students who have been assigned to the same job as part of the mandatory work-study program. What matters is that institutional details of the college suggest that randomness is a very reasonable way to characterize how students are assigned to groups. As mentioned in the Introduction, roommates are unconditionally randomly assigned to dorm rooms. ${ }^{8}$ Moreover, randomness is also a very good approximation

\footnotetext{
${ }^{7}$ The assumption of a constant variance can be motivated, in part, by the fact that, as described earlier, students at Berea have similar socio-economic backgrounds. This assumption also means that the variance of friendship quality does not depend on whether person $i$ is considering black or white potential friends. The analysis of this subsection can be modified to accommodate a model where students of the same race are heterogeneous with respect to $\mu$. However, the analysis of Section 4 depends on the assumption that $\mu$ is the same for students of the same race.

${ }^{8} \mathrm{~A}$ housing preference questionnaire is not used at Berea, apparently due to a belief that such questionnaires are of limited usefulness due to misreporting of behaviors such as smoking. Approximately two weeks before the start of school (and after all members of the freshman class have been determined) pairs of room-
} 
for assignment to work-study jobs (Stinebrickner and Stinebrickner (2003)) and the official orientation group.

Students choose friends in a two-stage process. First, after observing the race of each student in their orientation group, they select a group of $K<N$ individuals with whom to interact. For simplicity, we take $K$ to be the same for all students. Then they observe a signal $\xi_{j}$ of match quality for each person $j$ that is in their selected group and choose an individual of this group with whom to form a friendship. ${ }^{9,10}$ The first stage reflects the fact that each student encounters many other students during the orientation period, and so their interaction with some of them will necessarily be superficial, if it happens at all.

Finally, students are risk-neutral, i.e., they only care about the expected quality of a match, and myopic. We argue at the end of this section that the former assumption is as reasonable as any other in this specific context and that relaxing the latter assumption, which is made for convenience, would strengthen of our results.

Sorting We do not know how informative are the signals $\xi_{j}$ that a student observes in her chosen subgroup, in part because we do not know exactly how students allocate their time during the couple of days of the orientation period before they complete our baseline survey. In what follows we consider two alternatives that are amenable to a transparent analysis. mates were drawn from the pool of all freshmen using a random number generator or other procedure which ensures randomness. Stinebrickner and Stinebrickner (2004) provide indirect evidence of the randomness in the roommate assignment process by examining the correlation between several observable characteristics of students and their roommates. Not examined in Stinebrickner and Stinebrickner (2004) but of particular relevance here, we find no evidence of a relationship between a student's race and the race of her roommate.

${ }^{9}$ This is a weak view of friendship, where a friend is just someone that a person hangs around with or pays attention to. We do not mean for this assumption to be taken literally, although it would be broadly consistent with the notion that dorms at Berea are rather open places.

${ }^{10}$ We are implicitly assuming that a student always finds it desirable to form a friendship at the beginning of college. This corresponds to the extreme case where the value of not forming a friendship is $-\infty$. None of our conclusions depend on this particular assumption. 
We first consider the case where the signals $\xi_{j}$ provide little information about match quality. This, in essence, corresponds to the situation in which, during the orientation period, students are very busy registering for courses or performing other tasks in preparation for the start of courses so that they have little time to learn much more than the names of the people they have chosen for their subgroup. In this case, the only thing that matters for a student when selecting a subgroup with which to interact is the expected match quality of each individual in her orientation group. In particular, if a student has $m_{\mu}=0$, then she is indifferent among all the possible subgroups she can select and, once a subgroup is chosen, she is indifferent among all the individuals in her selected subgroup. Assuming that a student randomizes when indifferent, we have the following result.

Proposition 1. Suppose signals are not informative. Then, racial sorting can only be observed if some students have $m_{\mu}<0$ at the time they enter college. Therefore, if $\mu=0$ some students will be incorrectly pessimistic about the value of interracial friendship compatibility.

We now consider the polar case where the signals $\xi_{j}$ are very informative. This corresponds to the situation where each student spends much quality time with the students in her selected subgroup, and, as a result, is able to observe the true quality of the match with each of the individuals in this subgroup; i.e., $\xi_{j}=\theta_{j}$. The decision of which friendship to make once a subgroup is chosen is then straightforward: choose a member of the subgroup for which the match quality is the highest. What is left to determine is how students select their subgroups.

For this, notice that if individual $j$ in student $i$ 's orientation group is of the same race, then $i$ 's perception is that $\theta_{j} \sim N\left(0, \sigma_{v}^{2}\right)$, while if $j$ is of the opposite race, then $i$ 's perception is that $\theta_{j} \sim N\left(m_{\mu}, \sigma_{o}^{2}\right)$, where $\sigma_{o}^{2}=\sigma_{\mu}^{2}+\sigma_{v}^{2}$. Hence, if $m_{\mu}=0$, the distribution of possible 
match values for interracial friendships has the same mean, but fatter tails. Now notice that a student only cares about the highest match value in her selected subgroup. Hence, if she believes that the average match quality is the same for both races, then the greater the number of individuals of the opposite race that she selects the greater the chance that one of the people in her subgroup will turn out to be a very good match. Increasing the prior mean only reinforces the bias towards opposite race matches. More importantly, since expected payoffs are continuous in $m_{\mu}$, this bias persists if $m_{\mu}$ is not too negative. We then have the following result. Its proof and the proof of Proposition 2 below are in Appendix A.

Lemma 1. There is $\underline{m}<0$ such that if a student's prior mean is greater than $\underline{m}$, then it is optimal for her to select a subgroup with as many individuals of the opposite race as possible no matter the racial composition of her orientation group.

Now observe if $\mu=0$ for a student, so that there is no true difference in the distribution of match quality across races for her, then all individuals in her selected subgroup are equally likely to be chosen as a friend. The following result, Proposition 2, follows from this observation. Together with Proposition 1 they constitute the two main results of our model.

Proposition 2. Suppose that signals are sufficiently informative. If $\mu=0$ for both races, then racial sorting can only be observed if some students enter college with $m_{\mu}<0$, that is, if some students enter college incorrectly pessimistic about the value of interracial friendship compatibility.

\subsection{Discussion}

We end this section with a discussion of some of our modeling choices. We begin with the assumption that students are myopic. Since students believe it is possible that interracial 
matches are better than same-race ones, choosing someone of the opposite race to interact with provides valuable information for future friendship decisions. Hence, if a student is forward looking, she may be willing to sacrifice some of her payoffs during the orientation period and include more students of the opposite race in her subgroup than she would if she were myopic. This means that Propositions 1 and 2 not only do not depend on the assumption of myopic behavior, but the restrictions on $m_{\mu}$ and $\mu$ necessary to generate racial sorting are less stringent if students are forward looking.

We now discuss the assumption that students are risk neutral. What is important is that our context is quite different from other economic contexts where it is agreed that risk neutrality should be rejected in favor of the assumption of risk aversion. One reason that the marginal utility of friendship quality may not be decreasing over the relevant quality range is that some of the most valuable and rewarding benefits of friendship (e.g., sharing/confiding personal situations and problems) can only be realized with a friend of sufficiently high quality. Adding strength to the argument is the notion that the disutility from a bad match can be mitigated by ignoring that friend altogether, a solution that may not seem particularly problematic if one knows that more friendship opportunities are likely to arise soon. ${ }^{11}$ Thus, while it is impossible to know what characterization of risk is correct, it does not seem unreasonable to assume risk neutrality.

Finally we discuss what would happen if we were to relax the assumption that an individual observes only race when she first meets a potential friend. It is easy to see that our conclusions stay the same if, in addition to race, a person also observes a set of friendship-

\footnotetext{
${ }^{11}$ This points to another reason why students may be risk-neutral when choosing friends, namely, that friendship-making is truly a dynamic problem. Hence, even if the marginal utility of friendship quality is decreasing, the fact that new friendship opportunities are likely to arise soon after classes begin works as a form of insurance against bad friendship choices and may even encourage risk-taking behavior.
} 
relevant characteristics that are uncorrelated with race. Thus, the potentially relevant case is the one where observable characteristics are correlated with race. The discussion at the end of Subsection 3.1 provides evidence that this is not the case at Berea. Nevertheless, for the sake of illustration, consider the extreme case where the sorting by race in our data is generated by a situation in which individuals make friendship decisions based on an a single observable friendship-relevant characteristic that is strongly correlated with race. In this case, even though the individuals do not consider race in any way when making friendship decisions, they nevertheless believe that they are more compatible with individuals of the same race (as long as they notice that the characteristic is correlated with race). Thus, for our purposes, this case is no different than the one where individuals take into account race when making decisions because they believe that race is correlated with unobserved characteristics that are valuable. ${ }^{12}$ The open question remains whether or not, in reality, students are more compatible with students of the same race.

\section{Evidence About Interracial Compatibility}

In this section we provide evidence about $\mu$, the true value of average interracial friendship compatibility, by taking advantage of the fact that students are assigned roommates in an entirely random manner which, for example, does not take into account any characteristics or preferences of students. To the extent that sharing a room makes a non-trivial amount

\footnotetext{
${ }^{12}$ However, the two situations suggest different reasons for why a misperception might exist. In the case where decisions are made solely on the basis of an observed friendship characteristic that is correlated with race, misperceptions would have to arise because the characteristic is not as important for friendship quality as one expected. In the case where a person takes into account race when making decisions because she believes that race is correlated with unobserved characteristics that are valuable, misperceptions arise if the student is wrong about how race is correlated with these other unobserved characteristics.
} 
of interaction and observation unavoidable, this implies that some students are, in essence, forced to learn about their match quality with one randomly chosen roommate of the same race while other students are, in essence, forced to learn about their match quality with one randomly chosen roommate of a different race. We are particularly interested in whether $\mu=0$ since, in this case, the results in the previous section suggest that misperceptions about interracial friendship compatibility do exist.

It is plausible to assume that by some time $T$ sufficiently late in the first academic year each student $i$ has observed her match quality $\theta_{i, R}$ with her assigned roommate $R$. Then, comparing the average value of $\theta_{i, R}$ for roommate pairs where Race $_{i}=$ Race $_{R}$ to the average value of $\theta_{i, R}$ for roommate pairs where Race $_{i} \neq$ Race $_{\mathrm{R}}$ would provide direct evidence about whether $\mu=0$. In reality, we do not observe match quality directly, but we do observe whether a roommate eventually becomes a best friend. For the exercise here it is not necessary to describe how friendship decisions evolve over time between the beginning of the year and $T$. Rather, it is sufficient to note that at $T$ this process would produce a best non-roommate friend $B$. For simplicity, we assume that there is no uncertainty about $\theta_{i, B}$ at $T$. Then, information about whether roommates are best friends at $T$ yields an estimate of $\operatorname{Pr}\left(\theta_{i, R}>\theta_{i, B}\right)$ for roommate pairs where Race $_{i}=$ Race $_{R}$ and an estimate of $\operatorname{Pr}\left(\theta_{i, R}>\theta_{i, B}\right)$ for roommate pairs where Race $_{i} \neq$ Race $_{R}$. We reject the null hypothesis that individuals are, on average, equally compatible with students of the same race (i.e., the null hypothesis that $\mu=0)$ if these estimates allow us to reject the null hypothesis that $\operatorname{Pr}\left(\theta_{i, R}>\theta_{i, B}\right)$ is the same for roommate pairs where Race $_{i}=$ Race $_{R}$ as it is for roommate pairs where Race $_{i} \neq$ Race $_{R} \cdot{ }^{13}$ Similarly, we can also gain information about $\mu$ by examining whether a

\footnotetext{
${ }^{13}$ An implicit assumption is that the expected value of $\theta_{i, B}$ does not depend on whether a person's roommate is of the same race or a different race. The conclusion that we learn specifically about $\mu$ by comparing $\operatorname{Pr}\left(\theta_{i, R}>\theta_{i, B}\right)$ across same race and different race roommate pairs comes from our assumption that the
} 
roommate becomes one of a person's four friends. In this case, the inference concerns whether $\operatorname{Pr}\left(\theta_{i, R}>\theta_{i, B 4}\right)$ is the same for roommate pairs Race $_{i}=$ Race $_{R}$ as it is for roommate pairs where Race $_{i} \neq$ Race $_{R}$, where $B 4$ denotes the fourth best non-roommate friend alternative.

Specifically, we take advantage of the fact that we collected friendship data at multiple times each year and define our $T$ to correspond with the friendship survey that was collected at the end of the first semester. For the 2001 cohort we have 27 white students who were randomly assigned black roommates and 155 white students who were randomly assigned white roommates. For this cohort we find that that $44.4 \%$ of black roommates are listed as one of the four friends, $35.4 \%$ of white roommates are listed as one of the four friends, $18.5 \%$ of black roommates become best friends, and $18.7 \%$ of white roommates become best friends. ${ }^{14}$ Combining the 2000 and 2001 cohorts to increase the number of observations, we have 60 white students who were randomly assigned black roommates and 321 white students who were randomly assigned white roommates. For the combined cohorts we find that $35.0 \%$ of black roommates are listed as one of the four friends, $36.7 \%$ of white roommates are listed as one of the four friends, $16.7 \%$ of black roommates become best friends, and $16.5 \%$ of white roommates become best friends. ${ }^{15}$ Thus, because the sample proportions are always close for black and white roommates and are often higher for black roommates, we are never close to rejecting the null hypothesis that white students are equally compatible with black students as they are with other white students. Thus, our evidence suggests that $\mu=0$ for white students.

It is not possible to provide much information about how compatible black students are with other black students since the random assignment implies that only approximately variance of match quality does not depend on the race of one's potential friend.

${ }^{14}$ The standard errors associated with the proportions are .095, .038, .074, and .021 respectively.

${ }^{15}$ The standard errors associated with the proportions are $.061, .026, .020$, and .048 respectively. 
$(.158)^{2}=.025$ of all matches involve two black students. However, we can examine whether black students in the interracial pairs have views about their interracial roommates that are similar to those held by the white students in the interracial pairs. We find that this is the case. For the 2001 cohort we have 28 black students who were randomly assigned white roommates. We find that $39.3 \%$ of these roommates are listed as one of a the four friends (compared to a $44.4 \%$ report for white students in interracial pairs) and that $17.9 \%$ of these students become best friends (compared to $18.5 \%$ for white students in interracial pairs). ${ }^{16}$ Combining the 2000 and 2001 cohorts, we have 60 black students who were randomly assigned white roommates. We find that $35.0 \%$ of these roommates are listed as one of a the four friends (compared to $35.0 \%$ for white students in interracial pairs) and that $18.3 \%$ of these students become best friends (compared to $16.7 \%$ for white students in interracial pairs). ${ }^{17}$ Thus, it seems reasonable to conclude that $\mu=0$ for black students. This would be true, for example, if the compatibility of black students with other black students is the same as the compatibility of white students with other white students.

\section{Alternative Explanations}

While we think our model captures the fundamental features of the friendship-making process at the time of college entrance, it is worth considering possible changes to the model that might imply that our conclusions about beliefs would be wrong. One possibility is that social norms (social stigmas) imply that there is a cost to having both black friends and white friends. For example, if friends of one's own race criticize a student for having friends of a different race, then a person may not choose to have friends of both races even if he

\footnotetext{
${ }^{16}$ The standard errors associated with the proportions are .092 and .072 respectively.

${ }^{17}$ The standard errors associated with the proportions are .062 and .048 respectively.
} 
thinks that he is equally compatible with students of both races. However, there are a couple of things to note. First, if such a situation does exist, then it is strongly suggestive that at least some people on campus believe that blacks and whites are quite different and probably not particularly compatible - a view that is consistent with our conclusions about beliefs. Second, in such a situation, if, social norms aside, black students were truly indifferent between having black and white friends, our model suggests that they would choose to have only white friends since they are the majority group. Of course, this would not be the case if a black person with white friends is outwardly harassed on campus by black non-friends, but this is a view of things that seems very inconsistent with the environment at Berea. Thus, at least at Berea, this social norm view of things does not seem particularly satisfying. ${ }^{18}$ Another possibility, raised by Cornell and Welch (1996) in a labor market context, would be that students believe they are equally compatible with students of all races, but they are worse at evaluating their friendship compatibility with a person of a different race, making it more likely that students become friends with other students of the same race.

\section{Direct Evidence About Beliefs}

Sections 3 and 4 strongly suggest that some students (black or white or both) believe that, on average, they are more compatible with students of the same race than with students of other races at the time of college entrance. However, because, as illustrated by Section 5, it would never be possible to rule out with certainty all conceivable explanations for the observed sorting, it is desirable to provide direct evidence about this conclusion. An additional benefit

\footnotetext{
${ }^{18} \mathrm{~A}$ variant of this explanation would be that social stigmas are present because of the the views of parents. For example, a student who believes that she is equally compatible with students of all races might end up with more friends of the same race if it is unpleasant to introduce a friend of a different race to her family.
} 
of providing direct evidence is that, unlike the previous analysis, it potentially allows us to determine whether sorting is being generated by the preferences of white students, black students, or both.

The obvious difficulty in providing direct evidence about beliefs is that it is easy to imagine a variety of reasons that a person may consciously or subconsciously provide a biased view of her beliefs about interracial friendship compatibility if directly asked about this issue. We take a survey approach which utilizes the random assignment of roommates to circumvent this problem. At the beginning of classes, a recent cohort of Berea College Freshmen answered the following question:

Question B. The relationship students have with their roommates can possibly have an important effect on students' experiences during school. The following question is motivated by our interest in this issue.

If you were to ignore all outside pressures related to making friends, which of the following best describes your belief when you first saw your roommate before you got much of a chance talk to him/her or get to know him/her? Circle ONE

A. I thought it was very likely that this person would be a good match for me as a friend.

B. I thought it was somewhat likely that this person would be a good match for me as a friend.

C. I thought it was somewhat unlikely that this person would be a good match for me as a friend.

D. I thought it was very unlikely that this person would be a good match for me as a friend.

The appeal of this survey question is that the issue of race is not mentioned in any way, although later we describe why our results have value even if some individuals interpret this question as one about race. In addition, by asking students to "ignore all outside pressures" we hope to remove any possible consideration of social stigmas in their responses. 
Clearly there would be little value in our question if students had directly chosen their own roommates. Even if this is not the case, the value of our question would depend on what was observed at the time a person "first saw her roommate" if administrators used, for example, a housing preference questionnaire. ${ }^{19}$ Thus, it is beneficial that, with the unconditional random assignment, the question allows us to document the unconditional distribution of views that a particular racial group has (at the time of initial meetings) about compatibility with individuals of the same race and the opposite race.

Table 4 shows the results separately by race. A comparison of the first two columns allows us to examine whether white students believe that they are more compatible with other white students than black students. We find strong evidence that this is not the case. Indeed, the sample proportion of white students who believed that their white roommate was very likely to be a good match is smaller than the sample proportion of white students who believed that their black roommate was very likely to be a good match $(24.6 \%$ versus $34.4 \%$ ). However, what is striking in Table 4 is the evidence that black students are not nearly as optimistic about interracial compatibility. While $34.4 \%$ of white students believed that their randomly assigned black roommate was very likely to be a good match, only $9.70 \%$ of black students (in the same pairs) believed that their randomly assigned white roommate was very likely to be a good match. A test of the null hypothesis that white students are equally likely as black students to believe that a roommate of a different race is very likely to be a good match is rejected at all levels of significance greater than .018. It is not possible

\footnotetext{
${ }^{19}$ If all that is observed when students first see each other is race, then it would not make a difference if students were matched by administrators on the basis of a characteristic such as smoking behavior. However, if, in this example, smoking behavior is observable (and valued) when two roommates first see each other, then one would expect views in a case where an administrator tries to achieve compatibility to be different than the unconditional views.
} 
for us to observe how positive black students are about their compatibility with other black students since random assignment implies the data contain only a very small number of black-black roommate pairs. However, under the seemingly natural assumption that black students are (at least) as optimistic about their compatibility with other black students as white students are about their compatibility with black students, the test above implies that we would reject the null hypothesis that black students believe that they are as compatible with white students as they are with black students.

Thus, we are able to provide some direct evidence that our conclusion that some students believe that they are more compatible with students of the same race is correct and provide a suggestion that, at least in this case, it may be the minority group that has the incorrect perception.

We note that it is at least possible that some students view Question B as one about race. In this case, we would expect that the answers we receive would tend to overstate enthusiasm about students from different races. If this was a concern then we would not be able to conclude that white students are equally optimistic about black students as they are about other white students. However, our direct evidence that the minority students are too pessimistic about their match quality with white students would be strengthened further.

\section{Conclusion}

In order to think about how the specific results here might generalize, it is worth taking into account the discussion in the introduction which suggested that students who select Berea might tend to be relatively informed about interracial compatibility. This would suggest that our finding that the majority group at Berea is correctly optimistic about interracial 
friendship compatibility might not be true everywhere. However, it would also suggest that our finding that the minority group at Berea is incorrectly pessimistic about interracial friendship compatibility might be strengthened elsewhere. Of course, it is also possible that the true value of interracial friendship compatibility might be different at Berea than it is elsewhere. Viewed in a most cautious light, our results provide evidence of the existence of situations where there might be a potentially important role for affirmative action policies and that, while typically not the focus of public discussion, these policies might produce benefits for the minority group.

An important question which is not the primary focus of this paper, but has been examined in the work described in the Introduction, is whether affirmative action policies can be effective in alleviating misperceptions that might exist. In terms of looking for evidence of the effectiveness of such policies in our case, it would seem reasonable to conclude that perceptions about interracial friendship compatibility change over time at Berea if the amount of racial sorting was observed to decrease over time. However, Table 5 and Table 6, which recompute the sorting information shown in the first columns of Table 2 and Table 3 at multiple times during a student's career indicates that, in the sample, the amount of sorting actually increases slightly over time. It is worth stressing that this does not necessarily imply that beliefs are remaining the same. Even if beliefs about friendship compatibility change over time, substantial sorting may persist because either friendships made at the beginning of school tend to be permanent in nature or because initial friendship decisions play an important role in determining the network through which a person meets potential friends after the beginning of classes. ${ }^{20}$ Thus, it is necessary to view these results with substantial

\footnotetext{
${ }^{20}$ With respect to churning in friendships, only $.223, .104$, and .081 of the students listed as friends at the start of classes are also listed as friends at the middle of the first year, the middle of the second year, and the middle of the third year, respectively. With respect to the role of friendship networks in new friendships,
} 
caution. With respect to the policy effect of randomly assigning roommates in our case, we find that about half of the cases where best friends are of different races arise because these students were assigned as roommates but we find no evidence that assigning a student a roommate of a different race increases the number of other friends she has of that race.

\section{References}

[1] Arcidiacono, Peter, Shakeeb Khan, and Jacob Vigdor, "Representation versus dissimilation: How do preferences in college admissions affect social interactions," working paper, 2006.

[2] Boisjoly, Johanne, Greg Duncan, Michael Kremer, Dan Levy, and Jacque Eccles, "Empathy or antipathy? The impact of Diversity," forthcoming, American Economic Review.

[3] Cornell, Brad and Ivo Welch, "Culture, Information and Screening Discrimination," Journal of Political Economy, 104 (1996), 542-571.

[4] Charles, Kerwin, Erik Hurst, and Melvin Stephens, "Exploring Racial Differences in Vehicle Loan Rates," working paper, 2006.

[5] Fryer, Roland, and Paul Torelli, "An Empirical Analysis of Acting White," Working paper, (2006).

[6] Marmaros, David, and Bruce Sacerdote, "How Do Friendships Form?" The Quarterly Journal of Economics, February (2006), 79-119.

we find that the probability that a new friend of person i in a particular period is a friend of any of person i's friends in the previous period is typically around .10 . 
[7] Mayer, Adalbert, and Steven Puller, "The Old Boy (and Girl) Network: Social Network Formation on University Campuses," Working paper, Texas A\&M University, December, 2006.

[8] Stinebrickner, Todd, and Ralph Stinebrickner, "Time-use and college outcomes," Journal of Econometrics, 121 (2004), 243-269.

[9] Stinebrickner, Todd, and Ralph Stinebrickner, "Working during school and academic performance," Journal of Labor Economics, 21(2) (2003), 473-491.

[10] Stinebrickner, Todd, and Ralph Stinebrickner, "What can be learned about peer effects using college roommates? Evidence from new survey data and students from disadvantaged backgrounds," Journal of Public Economics, 90 (2006a), 1435-1454.

[11] Stinebrickner, Todd, and Ralph Stinebrickner, "Credit Constraints and College Attrition." working paper, The University of Western Ontario, 2006b. 


\section{Appendix A}

Proof of Lemma 1: Suppose that a student's orientation group has $n \geq 1$ individuals of the opposite race and consider a policy that selects a subgroup with $r$ of them. Notice that $r$ is at most $\bar{r}(n)=\min \{n, K\}$. Now observe that conditional on race, all members of a student's orientation group look the same before she selects which subgroup to interact with. Hence, any policy that selects $r$ individuals of the opposite race has the same expected payoff, that we denote by $u\left(r \mid n, m_{\mu}, \sigma_{\mu}^{2}\right)$ since it also depends on a student's prior mean and variance. Let $X_{m, \sigma^{2}}$ denote the normal random variable with mean $m$ and variance $\sigma^{2}$. Then, by construction,

$$
u\left(r \mid n, m_{\mu}, \sigma_{\mu}^{2}\right)=\int \max \left\{z_{1}, \ldots, z_{K}\right\} d X_{m_{\mu}, \sigma_{o}^{2}}\left(z_{1}\right) \cdots d X_{m_{\mu}, \sigma_{o}^{2}}\left(z_{r}\right) d X_{0, \sigma_{v}^{2}}\left(z_{r+1}\right) \cdots d X_{0, \sigma_{v}^{2}}\left(z_{K}\right)
$$

where we recall that $\sigma_{o}^{2}=\sigma_{v}^{2}+\sigma_{\mu}^{2}$.

We now show that there is $\underline{m}<0$ such that if $m_{\mu}>\underline{m}$, then $u\left(r \mid n, m_{\mu}, \sigma_{\mu}^{2}\right)$ is strictly increasing in $r$ for all $n \in\{1, \ldots, N\}$. For this observe that: (i) $X_{m_{1}, \sigma^{2}}$ first order stochastically dominates $X_{m_{2}, \sigma^{2}}$ if $m_{1}>m_{2}$; and (ii) $X_{m, \sigma_{1}^{2}}$ second order stochastically dominates $X_{m, \sigma_{2}^{2}}$ if $\sigma_{1}^{2}>\sigma_{2}^{2}$. Moreover, $\max \{a, z\}$ is increasing and convex in $z$ for all $a \in \mathbb{R}$. Hence, $m_{\mu} \geq 0$ implies that

$$
\begin{aligned}
u(r \mid & \left.n, m_{\mu}, \sigma_{\mu}^{2}\right)= \\
& =\int \max \left\{z_{1}, \ldots, z_{K}\right\} d X_{m_{\mu}, \sigma_{o}^{2}}\left(z_{1}\right) \cdots d X_{m_{\mu}, \sigma_{o}^{2}}\left(z_{r}\right) d X_{0, \sigma_{v}^{2}}\left(z_{r+1}\right) \cdots d X_{0, \sigma_{v}^{2}}\left(z_{K}\right) \\
& \geq \int \max \left\{z_{1}, \ldots, z_{K}\right\} d X_{m_{\mu}, \sigma_{o}^{2}}\left(z_{1}\right) \cdots d X_{m_{\mu}, \sigma_{o}^{2}}\left(z_{r-1}\right) d X_{0, \sigma_{o}^{2}}\left(z_{r}\right) d X_{0, \sigma_{v}^{2}}\left(z_{r+1}\right) \cdots d X_{0, \sigma_{v}^{2}}\left(z_{K}\right) \\
& >\int \max \left\{z_{1}, \ldots, z_{K}\right\} d X_{m_{\mu}, \sigma_{o}^{2}}\left(z_{1}\right) \cdots d X_{m_{\mu}, \sigma_{o}^{2}}\left(z_{r-1}\right) d X_{0, \sigma_{v}^{2}}\left(z_{r}\right) d X_{0, \sigma_{v}^{2}}\left(z_{r+1}\right) \cdots d X_{0, \sigma_{v}^{2}}\left(z_{K}\right) \\
& =u\left(r-1 \mid n, m_{\mu}, \sigma_{\mu}^{2}\right),
\end{aligned}
$$

where the first inequality follows from (i) and the second inequality follows from (ii) and the 
fact that $\int \max \{0, z\} d X_{0, \sigma^{2}}=\sqrt{\sigma / 2 \pi}$ is strictly increasing in $\sigma$. The desired result is then a consequence of the fact that the functions $u\left(r \mid n, m_{\mu}, \sigma_{\mu}^{2}\right)$ are continuous in $m_{\mu}$. Notice that $\underline{m}$ depends on $\sigma_{\mu}^{2}$.

Corollary 1. Suppose that $\mu=0$ for a student. There is $\underline{m}<0$ such that if this student is black (white) and has $m_{\mu}>\underline{m}$, then the probability that she has a black friend at the end of the orientation period is less (more) than the fraction of black students in college.

Proof: Let $\pi(\omega, r \mid \mu)$ be the probability, as a function of $\mu$, that a student of race $\omega$ chooses a black student as a friend when the subgroup she selects has $r$ such students. It is wellknown that if $Z_{1}$ to $Z_{n}$ are independent draws from the same real-valued random variable $Z$, then $\operatorname{Pr}\left[\max \left\{Z_{1}, \ldots, Z_{r}\right\} \geq \max \left\{Z_{r+1}, \ldots, Z_{n}\right\}\right]=r / n$ if $Z$ has no mass points. Hence, $\pi(\omega, r \mid 0)=r / K$. Now let $b$ be the fraction of black students in college and let $\Pi\left(\omega, m_{\mu}, \sigma_{\mu}^{2} \mid \mu\right)$ be the probability, as a function of $\mu$, that during the orientation period a student of race $\omega$, prior mean $m_{\mu}$, and prior variance $\sigma_{\mu}^{2}$ chooses a black student as a friend. By Lemma 1 , there exists $\underline{m}=\underline{m}\left(\sigma_{\mu}^{2}\right)<0$ such that if $m_{\mu}>\underline{m}$, then $\Pi\left(\right.$ white, $\left.m_{\mu}, \sigma_{\mu}^{2} \mid 0\right)=\sum_{n=0}^{N}\left(\begin{array}{c}N \\ n\end{array}\right) b^{n}(1-b)^{N-n} \pi($ white, $\bar{r}(n) \mid 0)>\frac{1}{K} \sum_{n=0}^{N}\left(\begin{array}{c}N \\ n\end{array}\right) n b^{n}(1-b)^{N-n}>b$, where the first inequality follows from the assumption that $K<N$. Recall that $\bar{r}(n)=$ $\min \{n, K\}$ is the maximum number of individuals of the opposite race that a student can select when her orientation has $n$ such students. Similarly, $m_{\mu}>\underline{m}$ implies that

$$
\Pi\left(\text { black, } m_{\mu}, \sigma_{\mu}^{2} \mid 0\right)=\sum_{n=0}^{N}\left(\begin{array}{c}
N \\
n
\end{array}\right)(1-b)^{n} b^{N-n} \pi(\text { black, } K-\bar{r}(n) \mid 0)<b
$$

Proof of Proposition 2: Proposition 2 follows immediately from Corollary 1. 
It is important to note that Proposition 2 also holds if $\mu$ is close to zero. This is follows from the fact that the probabilities $\pi(\omega, r \mid \mu)$ are continuous functions of $\mu$, and so are the probabilities $\Pi\left(\omega, m_{\mu}, \sigma_{\mu}^{2} \mid \mu\right)$. Indeed, let $m^{*}<0$ be the maximum among all students in college of the cutoff $\underline{m}$ given by Lemma $1 .{ }^{21}$ Then, $m_{\mu}>m^{*}$ implies that $\lim _{\mu \rightarrow 0} \Pi\left(\right.$ white, $\left.m_{\mu}, \sigma_{\mu} \mid \mu\right)>b$ and $\lim _{\mu \rightarrow 0} \Pi\left(\right.$ black, $\left.m_{\mu}, \sigma_{\mu} \mid \mu\right)<b$. Hence, for $\mu>m^{*}$ and close to zero, we can only observe racial sorting at the end of the orientation period if a large number of students enters college with a prior mean lower than $m^{*}$, and so lower than $\mu^{*}$.

${ }^{21}$ Notice that $\underline{m}$ also depends on $\sigma_{v}^{2}$. Hence, if students were to differ in $\sigma_{v}^{2}$ there would be no change in the proof of Proposition 2 other than that the value of $m^{*}$ would be different. 
Table 1 Descriptive Statistics - 2001 cohort

\begin{tabular}{|l|l|}
\hline \multicolumn{1}{|l|}{} & $\begin{array}{l}\text { Beginning } \\
\text { of College }(\mathrm{t}=0) \\
\mathrm{n}=375\end{array}$ \\
\hline Male & .432 \\
\hline Black & .158 \\
\hline High school grade point average & $3.37(.48)$ \\
\hline American College Test (ACT) & $23.34(3.63)$ \\
\hline physical attractiveness at college entrance & $2.642(.734)$ \\
\hline population density of home county & $363.293(535.116)$ \\
\hline family income at college entrance & $25238(18079.66)$ \\
\hline athlete in first year & .189 \\
\hline
\end{tabular}

The table shows the mean (standard deviation) for 2001 Berea Panel Study cohort (n=375).

Table 2

The proportion of students who have black best friends at start of classes in the freshman year Separately by race of student

\begin{tabular}{|l|l|l|}
\hline & $\begin{array}{l}\mathrm{n}=298 \text { (white) } \\
\mathrm{n}=56 \text { (black) }\end{array}$ & $\begin{array}{l}\mathrm{n}=269 \text { (white) } \\
\mathrm{n}=55 \text { (black) }\end{array}$ \\
\hline Black & $.696^{*}(.061)$ & $.676^{*}(.071)$ \\
\hline White & $.057^{*}(.013)$ & $.063^{*}(.023)$ \\
\hline & & \\
\hline Male & & $.009(.033)$ \\
\hline (Population density-363.29)/100 & & $.002(.004)$ \\
\hline Athlete in first year & & $-.048(.045)$ \\
\hline (Family income -25239)/10000 & & $.0005(.008)$ \\
\hline ACT-23.34 & & $-.006(.003)$ \\
\hline High school grade point average -3.37 & & $.041(.037)$ \\
\hline $\mathrm{R}^{2}$ & & .516 \\
\hline
\end{tabular}

Note. The first entry in the first column shows that the sample proportion of black students who have black best friends at the start of classes in the freshman year is .696 (Question A). The second entry in the first column shows the sample proportion of white students who have black best friends at the start of classes in the freshman year is .057 (Question A). The second column uses a linear probability model (with whether a person's best friend is black as the dependent variable) to also control for other observable characteristics of the student. The sample size is smaller in the second column due to the fact that some of the additional variables are missing for some individuals.

* Significant at $5 \%$ 
Table 3

The proportion of all listed friends who are black at the start of classes in the freshman year

Separately by race of student

\begin{tabular}{|l|l|l|}
\hline & $\begin{array}{l}\mathrm{n}=298 \text { (white) } \\
\mathrm{n}=56 \text { (black) }\end{array}$ & $\begin{array}{l}\mathrm{n}=269 \text { (white) } \\
\mathrm{n}=55 \text { (black) }\end{array}$ \\
\hline Black & $.668^{*}(.046)$ & $.640^{*}(.059)$ \\
\hline White & $.098^{*}(.012)$ & $.127^{*}(.020)$ \\
\hline Male & & \\
\hline (Population density-363.29)/100 & & $-.014(.029)$ \\
\hline Athlete in first year & & $.004(.003)$ \\
\hline (Family income -25239)/10000 & & $-.074(.034)^{*}$ \\
\hline ACT-23.34 & & $-.009(.007)$ \\
\hline High school grade point average -3.37 & & $-.003(.003)$ \\
\hline $\mathrm{R}^{2}$ & & $-.012(.033)$ \\
\hline
\end{tabular}

Note. The first entry in the first column shows that, on average, black students report (Question A) that $66.8 \%$ of all of their friends are black at the start of classes in the freshman year. The second entry in the first column shows that, on average, white students report (Question A) that 9.8\% of all of their friends are black at the start of classes in the freshman year. The second column uses a regression model (with the proportion of a person's reported friends who are black as dependent variable) to also control for other observable characteristics of the student .

* Significant at 5\%

Table 4. Responses to Question B

\begin{tabular}{|l|l|l|l|}
\hline & $\begin{array}{l}\text { White Students with } \\
\text { White Roommates } \\
\mathrm{n}=114\end{array}$ & $\begin{array}{l}\text { White Students With } \\
\text { Black Roommates } \\
\mathrm{n}=32\end{array}$ & $\begin{array}{l}\text { Black Students with } \\
\text { White Roommates } \\
\mathrm{n}=31\end{array}$ \\
\hline $\begin{array}{l}\text { Very likely roommate } \\
\text { will be good match }\end{array}$ & .246 & .344 & .097 \\
\hline $\begin{array}{l}\text { Somewhat likely roommate will } \\
\text { be good match }\end{array}$ & .518 & .531 & .581 \\
\hline $\begin{array}{l}\text { Somewhat unlikely roommate } \\
\text { will be good match }\end{array}$ & .157 & .062 & .258 \\
\hline $\begin{array}{l}\text { Very unlikely roommate } \\
\text { will be a good match }\end{array}$ & .079 & .062 & .064 \\
\hline & & & \\
\hline
\end{tabular}


Table 5

The proportion of students who have black best friends at various times during college

Separately by race of student

\begin{tabular}{|l|l|l|l|l|}
\hline & $\begin{array}{l}\text { Start of classes } \\
\text { freshman year } \\
\mathrm{n}=298 \text { (white) } \\
\mathrm{n}=56 \text { (black) }\end{array}$ & $\begin{array}{l}\text { Middle of } \\
\text { freshman year } \\
\mathrm{n}=279 \text { (white) } \\
\mathrm{n}=56 \text { (black) }\end{array}$ & $\begin{array}{l}\text { Middle of } \\
\text { sophomore year } \\
\mathrm{n}=229 \text { (white) } \\
\mathrm{n}=46 \text { (black) }\end{array}$ & $\begin{array}{l}\text { Middle of } \\
\text { junior year } \\
\mathrm{n}=202 \text { (white) } \\
\mathrm{n}=36 \text { (black) }\end{array}$ \\
\hline Black & $.696(.061)$ & $.767(.056)$ & $.804(.058)$ & $.805(.066)$ \\
\hline White & $.057(.013)$ & $.050(.013)$ & $.065(.036)$ & $.059(.039)$ \\
\hline & & & & \\
\hline
\end{tabular}

Note. The first entry in the first column shows that the sample proportion of black students who have black best friends at the start of classes in the freshman year is .696 (Question A). The second entry in the first column shows the sample proportion of white students who have black best friends at the start of classes in the freshman year is .057 (Question A). The second, third, and fourth columns show similar results in middle of the freshman year, middle of the sophomore year, and middle of the junior year, respectively. The decrease in the sample size over time occurs almost exclusively because of attrition out of college (response rates for second column, third column, and fourth column were $94 \%, 95 \%$, and $98 \%$, respectively. Results are very similar if one shows results using only individuals who are observed in all four time periods.

Table 6

The proportion of all listed friends who are black at various times during college

Separately by race of student

\begin{tabular}{|l|l|l|l|l|}
\hline & $\begin{array}{l}\text { Start of classes } \\
\text { freshman year } \\
\mathrm{n}=298 \text { (white) } \\
\mathrm{n}=56 \text { (black) }\end{array}$ & $\begin{array}{l}\text { Middle of } \\
\text { freshman year } \\
\mathrm{n}=279 \text { (white) } \\
\mathrm{n}=56 \text { (black) }\end{array}$ & $\begin{array}{l}\text { Middle of } \\
\text { sophomore year } \\
\mathrm{n}=229 \text { (white) } \\
\mathrm{n}=46 \text { (black) }\end{array}$ & $\begin{array}{l}\text { Middle of } \\
\text { junior year } \\
\mathrm{n}=202 \text { (white) } \\
\mathrm{n}=36 \text { (black) }\end{array}$ \\
\hline Black & $.668(.046)$ & $.654(.050)$ & $.766(.049)$ & $.708(.057)$ \\
\hline White & $.098(.012)$ & $.073(.009)$ & $.068(.009)$ & $.075(.011)$ \\
\hline
\end{tabular}

Note. The first entry in the first column shows that, on average, black students report (Question A) that $66.8 \%$ of all of their friends are black at the start of classes in the freshman year. The second entry in the first column shows that, on average, white students report (Question A) that 9.8\% of all of their friends are black at the start of classes in the freshman year. The second, third, and fourth columns show similar results in middle of the freshman year, middle of the sophomore year, and middle of the junior year, respectively. 